\title{
AN EXAMINATION OF NETWORK RTK GPS SERVICES IN GREAT BRITAIN
}

\author{
S. J. Edwards, P. J. Clarke, N. T. Penna and S. Goebell \\ School of Civil Engineering and Geosciences \\ Newcastle University \\ Newcastle upon Tyne \\ NE1 7RU \\ UK
}

\begin{abstract}
As of March 2009, network real-time kinematic (RTK) GPS surveying is available in Great Britain with the aid of two commercial service providers, Leica's "SmartNet" and Trimble's "VRS Now", both of which rely largely on the Ordnance Survey's "OS Net" network of around 120 continuously operating reference stations. With the aim of testing the performance of Network RTK under both ideal and less-ideal conditions (greater distances and elevation differences from the nearest reference stations, proximity to the edges of OS Net, and increased susceptibility to ocean tide loading effects), we have tested the positional accuracy of both commercial Network RTK systems by comparison with precise coordinates determined using the Bernese scientific GPS processing software, at six representative locations spanning England and Wales. We find that the coordinate quality measures provided by the Network RTK solutions are overall representative of the actual coordinate accuracy, which is typically 10-20 $\mathrm{mm}$ in plan and 15-35 $\mathrm{mm}$ in height, and can be successfully used to identify outliers. Positional accuracy tends to be poorest outside of the bounds of OS Net and at greater elevation differences from nearby reference stations. Averaging of coordinates over two short windows separated by 20-45 minutes can be used to achieve moderate improvements in coordinate accuracy without the need for single long occupations of sites.
\end{abstract}

KEYWORDS: GPS. Network real-time kinematic (RTK) positioning. Quality measures.

\section{INTRODUCTION}

Centimetre level positioning using single baseline real-time kinematic (RTK) GPS has seen significant uptake within the surveying and engineering communities since its introduction in the mid 1990s. Typical equipment configuration consists of a reference station, set up over a precisely coordinated point, which transmits code and carrier phase observations to a roving GPS unit in order for the rover's relative position to be determined on-the-fly. However, when baseline lengths increase beyond $10-20 \mathrm{~km}$, errors due to satellite orbit and atmospheric delay are no longer sufficiently mitigated by differencing, resulting in degraded position estimates and difficulty in resolving the integer ambiguities reliably. To overcome this limitation, the Network RTK concept has been developed, incorporating a network of reference stations that typically surround the rover. In one approach, the Master_Auxiliary Concept or MAC, atmospheric, orbit and clock errors are continuously estimated or modelled at these reference stations and are then transmitted together with the reference station data [1]. An alternative approach is to use the data from the reference stations to simulate the observations experienced at a "virtual" reference station (VRS) located at the rover's approximate position, and these virtual data are then transmitted and processed together with the rover data [2], [3]. Both approaches enable rover to reference station distances to be increased, but seek to maintain the positional accuracy obtainable from local reference station RTK.

An edited version of this paper was published as:

SJ Edwards, PJ Clarke, NT Penna and S Goebell (2010). An examination of network RTK

GPS services in Great Britain. Survey Review, 42(316), 107-121

(doi:110.1179/003962610X12572516251529). 
Multiple reference station RTK trials have been on-going since the late 1990s, for example in Singapore [4], [5], culminating in operational services being offered in many regions in recent years. For example, both Leica Geosystems and Trimble have provided such Network RTK services for the whole of Great Britain since early 2006, primarily using as reference stations the Ordnance Survey's national Continuously Operating Reference Station (CORS) GPS network known as OS Net, which has recently been upgraded to full GNSS capability. Indeed, the key driver for the densification of OS Net to more than 100 stations with a median inter-station spacing of just over $60 \mathrm{~km}$ was to facilitate Network RTK services. Hence the surveyor in Great Britain may as of March 2009 determine rover position using either Leica Geosystems' solution, which normally uses the MAC concept (termed 'SmartNet'), or Trimble's solution based on the virtual reference station concept (termed 'VRS Now'). Both providers claim similar position accuracies. For example, [6] state their system 'typically achieves an RTK rmse accuracy of 1-2 cm plan and 2-3 cm height'; [7] state that RMS vertical errors of always less than $3 \mathrm{~cm}$ were obtained from a $90 \mathrm{~km}$ reference station spacing configuration. Elsewhere, [8] performed an independent Network RTK accuracy assessment in the Marmara region of Turkey (approximately $300 \mathrm{~km}$ x $150 \mathrm{~km}$ ) that included Leica and Trimble's systems for average rover to reference station distances of up to around $60 \mathrm{~km}$, and generally found $80-90 \%$ of solutions had horizontal and vertical precisions better than $3 \mathrm{~cm}$ and $5 \mathrm{~cm}$ respectively. Here we provide further independent investigations of the accuracy and precision attainable from the Leica and Trimble services, with reference to their implementation in Great Britain, and suggest practical approaches to improving the robustness of the solution in terms of site occupation durations. Also considered is the sensitivity of Network RTK positional accuracy and precision to network edge effects (interpolation versus extrapolation of errors), height effects (i.e. effects of rover and reference station height differences) and ocean tide loading (OTL). Test sites across Great Britain were identified to assess the attainable precisions, accuracies and the effect of limiting factors, and large data samples were simultaneously collected using both the SmartNet and VRS Now services.

\section{NETWORK RTK SERVICES IN GREAT BRITAIN}

The VRS Now and SmartNet services adopt slightly different approaches in the provision of data to the rover, and additionally use slightly different reference station arrays. In Great Britain, the VRS Now service uses only the OS Net reference stations. The VRS approach can be categorised as a non-physical technique in which the software at the processing centre utilises observations from the reference stations to estimate the spatially varying dispersive and non-dispersive corrections to the observations in the vicinity of the roving receiver. Individual corrections are applied to interpolated reference station observations to form 'virtual GNSS observations' which are broadcast to the roving receiver. These corrected virtual observations simulate those that would be received by a permanent reference station located close to the roving receiver. Standard carrier phase double-differencing is undertaken between the roving receiver and this virtual reference station, with baseline lengths typically ranging from a few metres to several kilometres e.g. [9].

In contrast to the above, SmartNet normally uses the MAC technique, in which raw reference station observations and network information are broadcast separately. Here, dispersive and non-dispersive correction information for all auxiliary reference stations relative to one master reference station, together with that master station's full raw data and precise coordinates, are transmitted to the roving receiver. The roving receiver software is 
able to reconstruct the full network information and combine it with the dispersive and nondispersive error estimates during coordinate estimation. In essence, MAC data comprises the raw GNSS observations for the whole network minus nuisance parameters e.g. clock errors and ambiguities, [9]. In practice, only a subset (cell) of the total network of reference stations surrounding the roving receiver is used in position determination, thus reducing the required data transmission bandwidth. To provide extra redundancy, a small number of additional permanent reference stations are used to augment OS Net.

Within a typical Network RTK model the minimum configuration of CORS is three. These normally enclose the roving receiver within their perimeter, although extrapolation outside this zone is also possible. Generally, the roving receivers are required to transmit their approximate coordinates to the network data processing centre enabling the appropriate reference stations to be selected and corrections to be determined, [10]. Clearly, some form of communication is required between the roving receivers and the processing centre; in Great Britain both service providers use existing mobile telecommunication networks. Both SmartNet and VRS Now services have the potential to provide coverage across the whole of Great Britain as spanned by OS Net, however, the critical limiting factor is usually that of telecommunication coverage. Whilst remaining a significant issue for the user, this aspect of service provision has not been investigated in this work. We note that [11] and [12] recently carried out a study of this factor in isolation.

\section{TEST Sites AND DATA COLLECTION}

To test the performance of the SmartNet and VRS Now Network RTK services in Great Britain, six test sites in England and Wales were selected and, at each site during March/April 2008, 6 hours of Network RTK GPS data were simultaneously collected using each of the two services. We did not use any GLONASS data in this work, because OS Net had upgraded to GNSS capability in a limited area at the time of testing; nor did we investigate initialisation times, because this issue has previously been assessed by [3]. The sites were chosen with the aim of assessing where possible the generic Network RTK limiting factors of extrapolation from the reference station network boundaries, height-related atmospheric effects, and ocean tide loading. Thus:

- CALL was chosen as a site located relatively close to reference stations $(10 \mathrm{~km}$ from the nearest, mean $46 \mathrm{~km}$ from the nearest four) and in a location with an open aspect, in order to assess the solution quality and reliability under near-ideal conditions.

- STMG and TRET were selected since they were on the network extremities and therefore provided an indication of errors due to extrapolation rather than interpolation from reference station data. TRET was also incorporated since it is subject to fairly large ocean tide loading displacements which are expected to have an effect on relative position computation, as described in [13].

- TUSH and GWYN were selected to test the effects of tropospheric errors due to large elevation differences between the rover and reference stations. Both were located close (horizontally) to each other and at similar, moderately large, distances from the nearest reference stations, but GWYN was located $255 \mathrm{~m}$ on average above the four nearest reference stations, whilst TUSH had only a small mean elevation difference of $16 \mathrm{~m}$ relative to the four nearest reference stations.

- STRE was chosen to represent sites at a moderate distance from the nearest reference station, but large average elevation difference from surrounding stations. 
The sites selected are summarised in Table 1 and their locations displayed in Figure 1, which illustrates the average distance and elevation difference from the nearest four OS Net reference stations. Each site was an Ordnance Survey passive GPS network point, which meant they were all located away from urban canyons and were therefore relatively GPS 'friendly' sites, to obtain as consistent an environment as possible with which to assess the Network RTK position quality, and any spatially dependent limiting factors. At each test site, both a Leica and a Trimble receiver/antenna pair were set up, and SmartNet and VRS Now derived Network RTK positions in ETRF89 and Dilution of Precision (DOP) values were collected simultaneously every second for 6 hours. This enabled a large sample of positional solutions to be obtained whilst encompassing a variety of satellite geometric configurations. Also recorded were the raw GPS data (for post-processing 'truth' coordinate determination) and the manufacturer-generated coordinate quality (CQ) indicators in plan and in height. Manufacturer-recommended equipment configurations and settings were adhered to throughout, with an elevation angle mask of $10^{\circ}$ and a PDOP mask of 99 . In addition, the Trimble receiver filtered out solutions with a CQ greater than $0.1 \mathrm{~m}$ in either plan or height; the Leica receiver did not impose this filter in real time but it was later applied to the recorded solutions before further analysis took place. The two antennas were set up on a bar with a fixed inter-antenna distance of $250 \mathrm{~mm}$, and then mounted on a tripod centred over the Ordnance Survey passive station marker, as shown in Figure 2. For each test the bar was aligned to magnetic North with the Trimble antenna always set as the most northerly to ensure equipment configuration repeatability. A third (Leica AX1202) antenna was also set up in the middle of the bar and centred over the passive station marker, and recorded raw GPS data for the duration to allow for the accurate determination of truth coordinates.

Table 1. Test sites selected, including locations, orthometric height, mean distances and mean elevation differences to nearest four OS Net reference stations. Additional Network RTK limiting criteria being assessed are also listed.

\begin{tabular}{|c|c|c|c|c|c|c|c|c|}
\hline $\begin{array}{l}\text { Site } \\
\text { (identifier in } \\
\text { bold typeface) }\end{array}$ & $\begin{array}{l}\text { Lat } \\
\left({ }^{\circ} N\right)\end{array}$ & $\begin{array}{l}\text { Lon } \\
\left({ }^{\circ} E\right)\end{array}$ & $\begin{array}{l}\text { Height } \\
\text { (m) }\end{array}$ & $\begin{array}{l}\text { Distance } \\
\text { to } \\
\text { nearest } \\
\text { ref. sta. } \\
(\mathrm{km})\end{array}$ & $\begin{array}{l}\text { Mean } \\
\text { distance } \\
\text { to nearest } \\
4 \text { ref. sta. } \\
(\mathrm{km})\end{array}$ & $\begin{array}{l}\text { Mean } \\
\text { elevation } \\
\text { difference } \\
\text { to nearest } \\
4 \text { ref. sta. } \\
(m)\end{array}$ & $\begin{array}{l}\text { Obs. } \\
\text { date }\end{array}$ & $\begin{array}{l}\text { Criteria } \\
\text { assessed }\end{array}$ \\
\hline CALLerton & 55.0159 & 358.2457 & 116 & 10 & 46 & 53 & $17 / 03 / 08$ & $\begin{array}{l}\text { "Ideal" } \\
\text { conditions }\end{array}$ \\
\hline $\begin{array}{l}\text { STMG } \\
\text { (St Margarets) }\end{array}$ & 51.1462 & 1.3637 & 100 & 28 & 46 & -81 & $21 / 03 / 08$ & Extrapolation \\
\hline TRETio & 51.9187 & 354.7798 & 102 & 27 & 70 & -56 & $24 / 03 / 08$ & $\begin{array}{l}\text { Extrapolation, } \\
\text { OTL }\end{array}$ \\
\hline $\begin{array}{l}\text { Church } \\
\text { STREtton }\end{array}$ & 52.5300 & 357.2132 & 311 & 22 & 44 & -255 & $25 / 03 / 08$ & Heighting \\
\hline TUSHingham & 53.0028 & 357.2888 & 103 & 31 & 48 & 16 & $17 / 04 / 08$ & Heighting \\
\hline GWYNfryn & 53.0678 & 356.8889 & 357 & 45 & 66 & -254 & $18 / 04 / 08$ & $\begin{array}{l}\text { Heighting, } \\
\text { distance }\end{array}$ \\
\hline
\end{tabular}



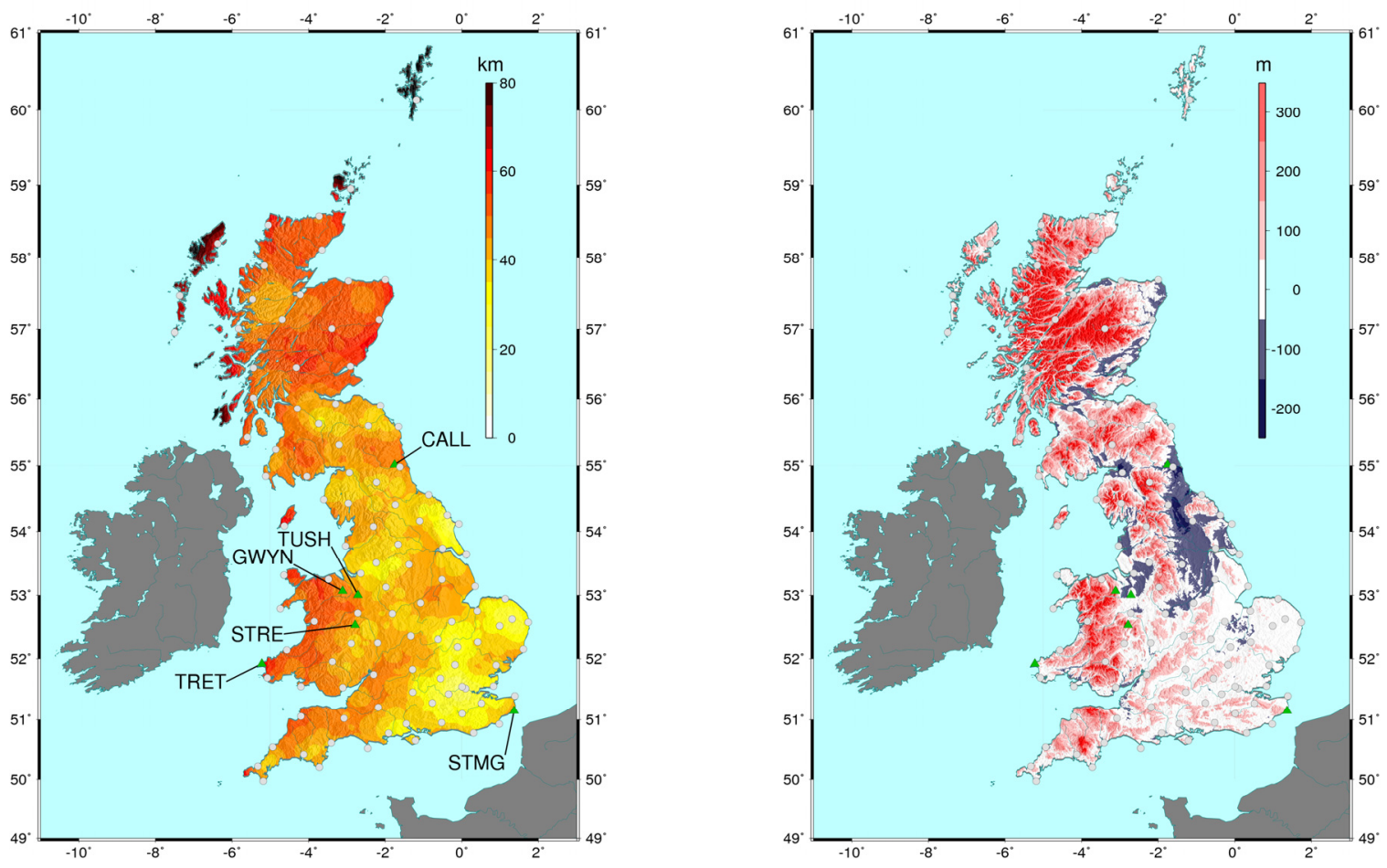

Fig. 1. Mean horizontal (left) and elevation (right) differences from nearest four Ordnance Survey reference stations (circles). The test sites selected are also shown (triangles)

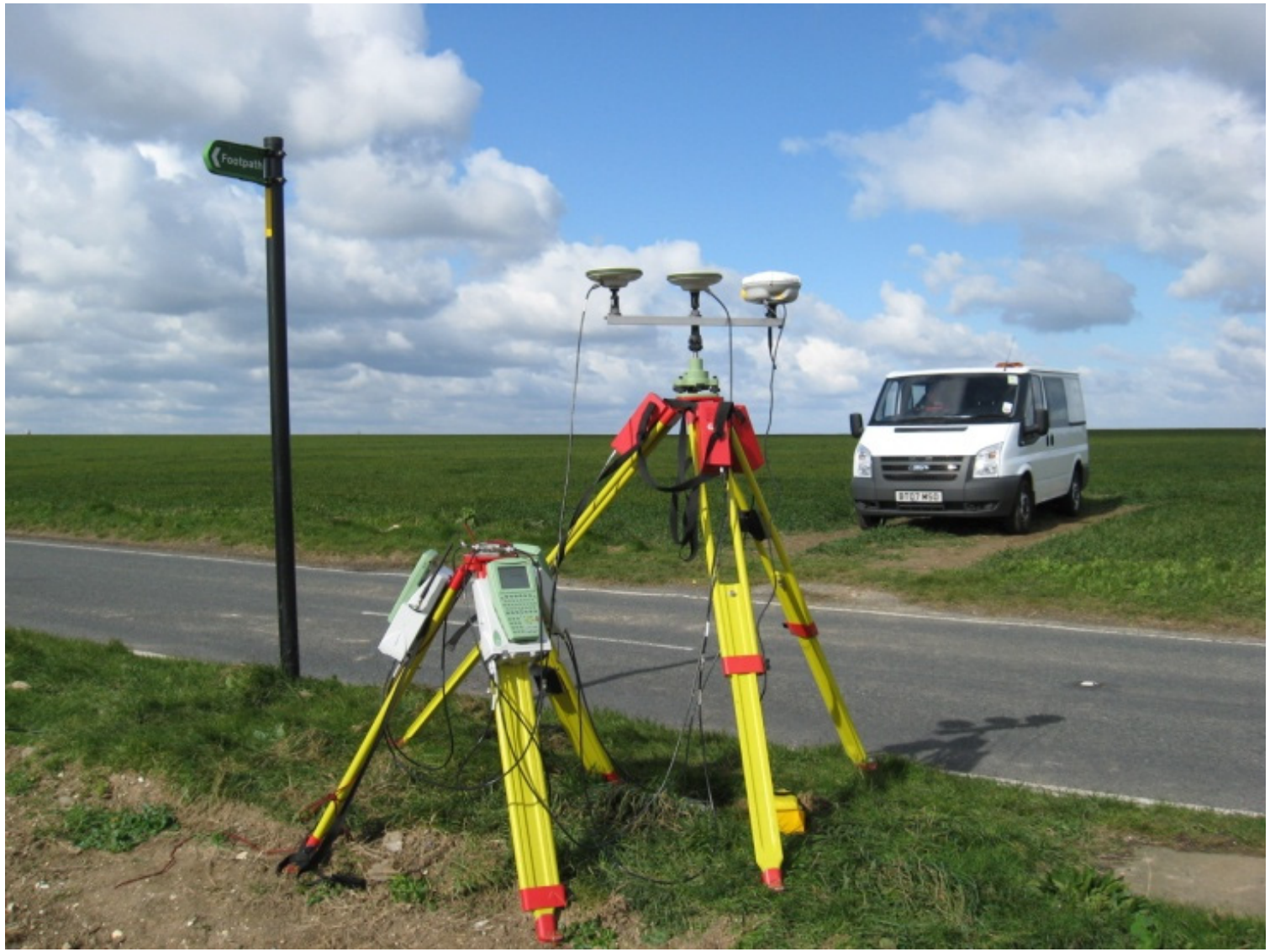

Fig. 2. Equipment configuration used for the data collection (shown at the STMG test site) 


\section{TRUTH COORDINATE DETERMINATION}

ETRF89 truth coordinates were computed for both the Leica and Trimble antennas at each test site, which then served as a reference for assessing the accuracy of the SmartNet and VRS Now positional estimates. To ensure the truth coordinates and Network RTK coordinates were in a compatible realisation of ETRF89, the 6 hours of static GPS data collected per site were geodetically processed relative to the four nearest OS Net reference stations, whose ETRF89 coordinates computed by the Ordnance Survey (http://www.ordnancesurvey.co.uk/oswebsite/gps/docs/OSNet_GPSWebSite_Coordinates_Fi le.TXT) were held fixed (as also in the Network RTK coordinate solutions). The Bernese v5.0 [14] scientific package was used, holding fixed the final IGS orbits and earth rotation parameters, applying the IGS absolute satellite and ground antenna variation models, estimating a zenith tropospheric delay parameter per site every 2 hours, and correcting for Earth tide and ocean tide loading displacements according to the IERS Conventions 2003 [15], with the aid of the FES2004 numerical ocean tide model [16]. The Niell [17], tropospheric mapping function was used with an elevation angle cut-off of $15^{\circ}$. Generally more than $90 \%$ of the integer ambiguities were fixed to integers, with the final solution being generated using the ionosphere-free linear combination of phase observables. Only for the coordination of STMG was ambiguity resolution less successful, at around the $60-70 \%$ mark. Before the final passive station coordinates were determined, a preliminary solution was obtained, in which the published coordinates of only the nearest reference station were fixed, and the other three (plus an additional check) reference stations' coordinates were estimated together with those of the passive station. Comparing the estimated reference station coordinates with the published values provided an accuracy assessment, with coordinate differences of less than $5 \mathrm{~mm}$ invariably obtained in all three components. This enabled the coordinates of the OS Net reference stations to be fixed with confidence in the final determination of each passive station's coordinates, and suggests their accuracy is better than $5 \mathrm{~mm}$.

The truth coordinates of the SmartNet and VRS Now antennas were then obtained by fixing the coordinates of the central antenna and processing as two very short $250 \mathrm{~mm}$ baselines. Leica GeoOffice software was used, with the solution derived using simultaneously the L1 and L2 observables, holding fixed the final IGS precise ephemerides with an elevation angle cut-off of $15^{\circ}$.

\section{POSITION QUALITY ATTAINABLE FROM SMARTNET AND VRS NOW SERVICES}

For each test site, the performance of the two systems was assessed by differencing the SmartNet and VRS Now derived coordinates from the truth coordinates, then computing the RMS and mean of these differences per component for the entire 6 hour data collection session. Before computing any statistics, we identified and removed probable outliers using two simple criteria which would be available to practitioners in the field. Firstly, outliers were eliminated using the reported CQ values. Any solutions with CQ values greater than $100 \mathrm{~mm}$ in height and $50 \mathrm{~mm}$ in horizontal were rejected. Since the solutions had, for consistency, been previously filtered with a CQ cut-off of $100 \mathrm{~mm}$ in each of plan and height, the number of data removed in this step was very small (less than $0.1 \%$ ). Typically these arise from cycle slips, loss of lock or data outages, resulting in failed ambiguity resolution. As good geometry is desired to ensure robustness in RTK surveying, and solutions are only usually accepted if this is so, the solutions were then further filtered according to DOP 
values, with a cut-off of PDOP less than three. The effects of such CQ and DOP filtering for the ideal conditions site CALL and for a more representative site TUSH are shown in Figures 3 and 4 respectively. Also shown are 5 minute running averages of the positional errors, to aid the visual identification of any trends. It can be seen by visual inspection that only a small proportion of solutions were rejected through this filtering and, as detailed in Table 2, over $95 \%$ of solutions were retained in all cases except GWYN which was marginally worse. The RMS position errors over the entire 6 hour session at each site are also listed in Table 2 . For the height component these are less than $30 \mathrm{~mm}$ in all cases (as low as $9 \mathrm{~mm}$ for the CALL SmartNet solution) whilst for the horizontal components they are 5-20 mm for all sites except for the East component at STMG, where they are around $30 \mathrm{~mm}$. Meanwhile the mean coordinate differences from the truth are generally less than $15 \mathrm{~mm}$ in height (only the SmartNet solutions at GWYN and STMG exceed this with $21 \mathrm{~mm}$ and $24 \mathrm{~mm}$ respectively) and less than $15 \mathrm{~mm}$ in the horizontal components everywhere. These position errors clearly indicate that the manufacturers' claimed Network RTK precisions and accuracies are realistic, at least for the relatively benign environments tested here, whether for sites ideally located close to reference stations, or surrounded by reference stations at some distance, or those on the edges of the network.
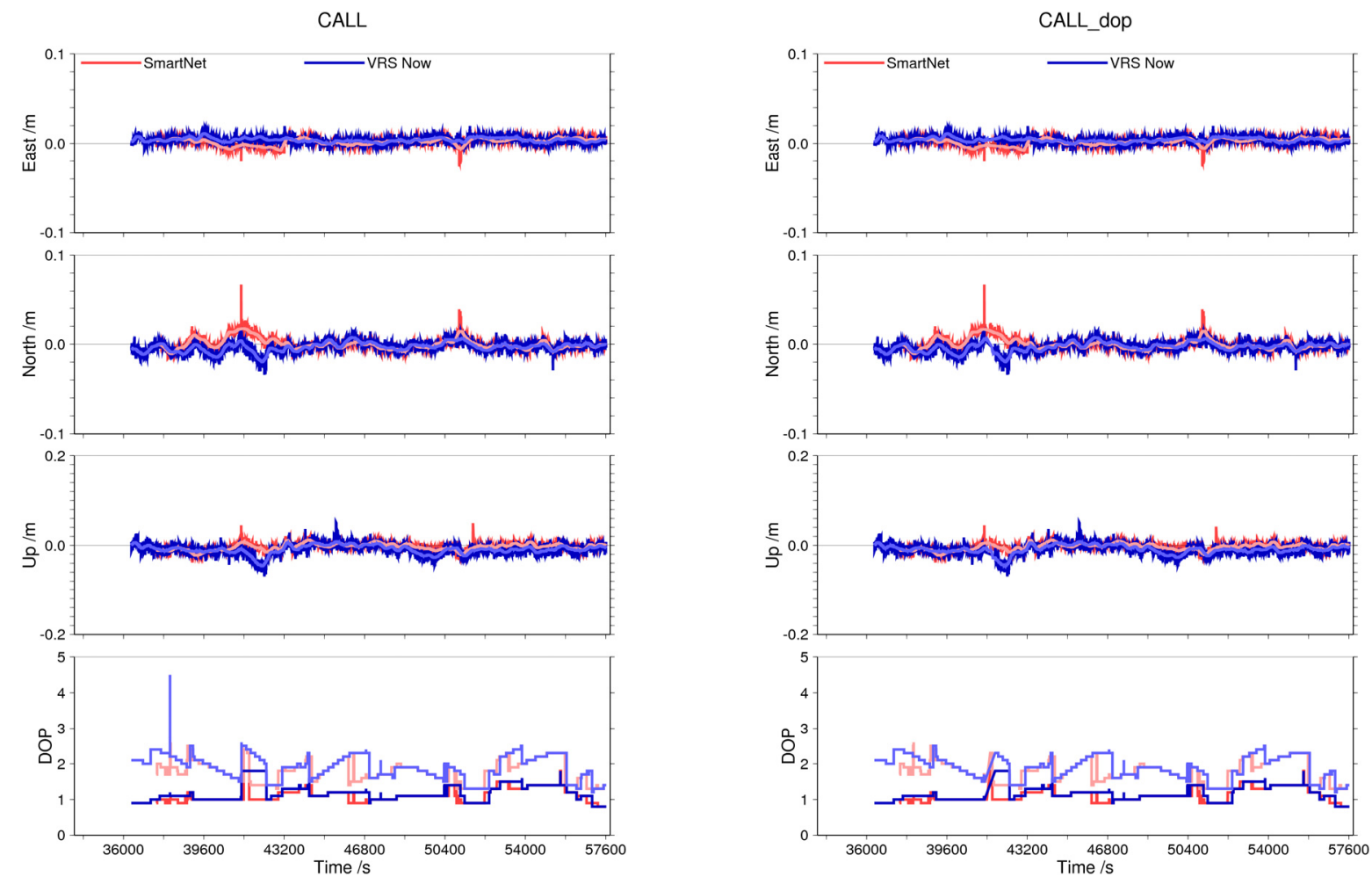

Fig 3. Time series of position errors (Network RTK solution minus truth coordinate) for the CALL test site, with 5 minute running averages (thick lines). On the left are the raw solutions, whilst on the right are the solutions filtered according to CQ indicators and DOP values. 

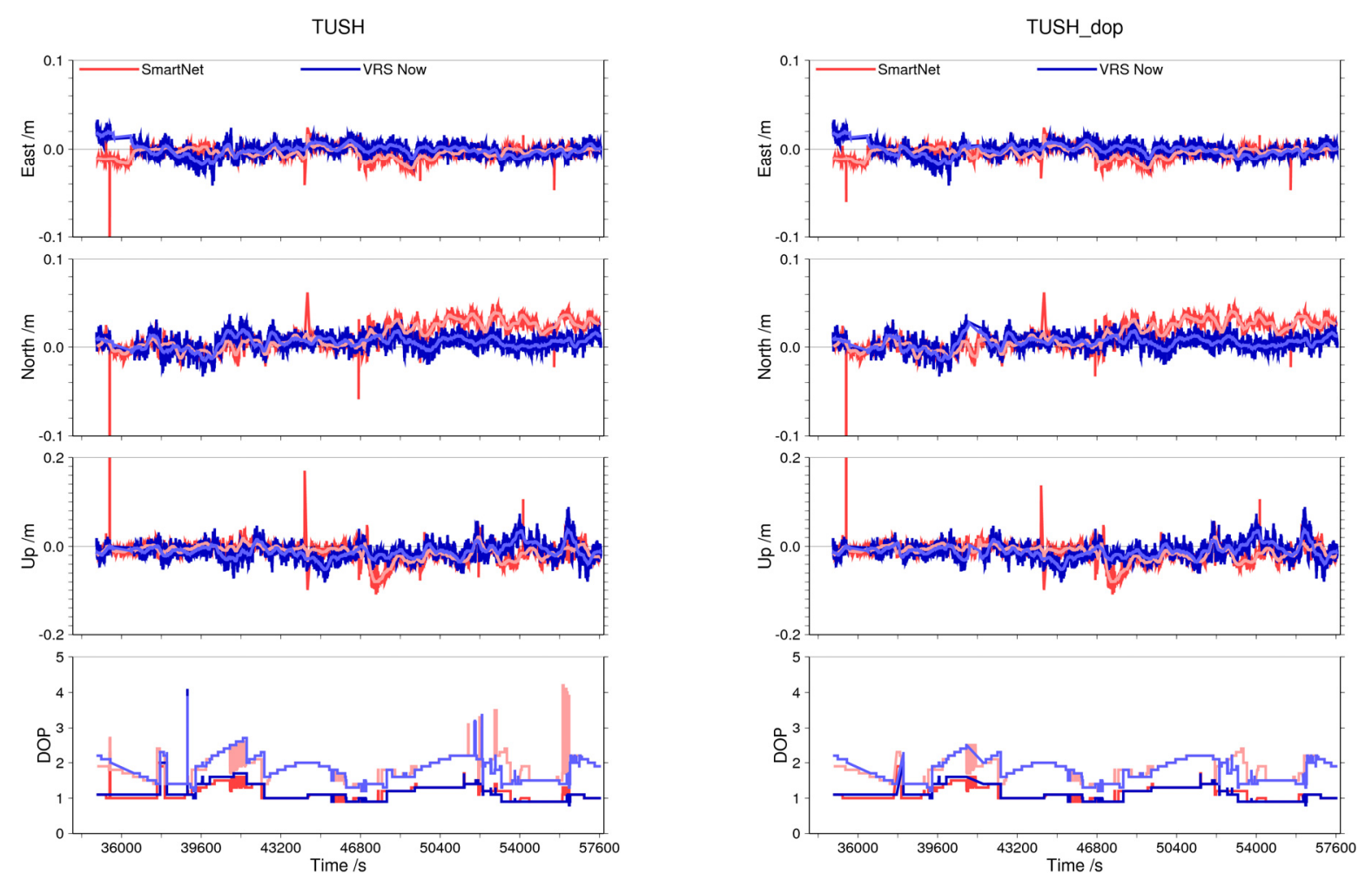

Fig 4. Time series of position errors (Network RTK solution minus truth coordinate) for the TUSH test site, with 5 minute running averages (thick lines). On the left are the raw solutions, whilst on the right are the solutions filtered according to CQ indicators and DOP values.

The manufacturer-derived CQ indicators are the main source of position quality information available to the field surveyor. To assess their reliability, they were compared with the RMS of the positional errors computed in 5 minute sliding windows for the entire time series, for each coordinate component. These, together with the manufacturer's CQ values are shown for CALL and TUSH in Figure 5 and the ratios of RMS position error to CQ value are plotted in Figure 6. It can be seen for the ideal conditions test site CALL that the ratios are generally very close to unity for both the SmartNet and VRS Now services, and therefore here the manufacturer's CQ values are reasonably representative of the one-sigma coordinate standard errors. At TUSH, the ratio is still centred roughly around unity, but there are both short and longer term excursions from unity, meaning that they should not be fully relied upon to identify coordinate quality unless surveying in ideal GPS observing conditions. The mean RMS/CQ ratios are detailed in Table 2. 

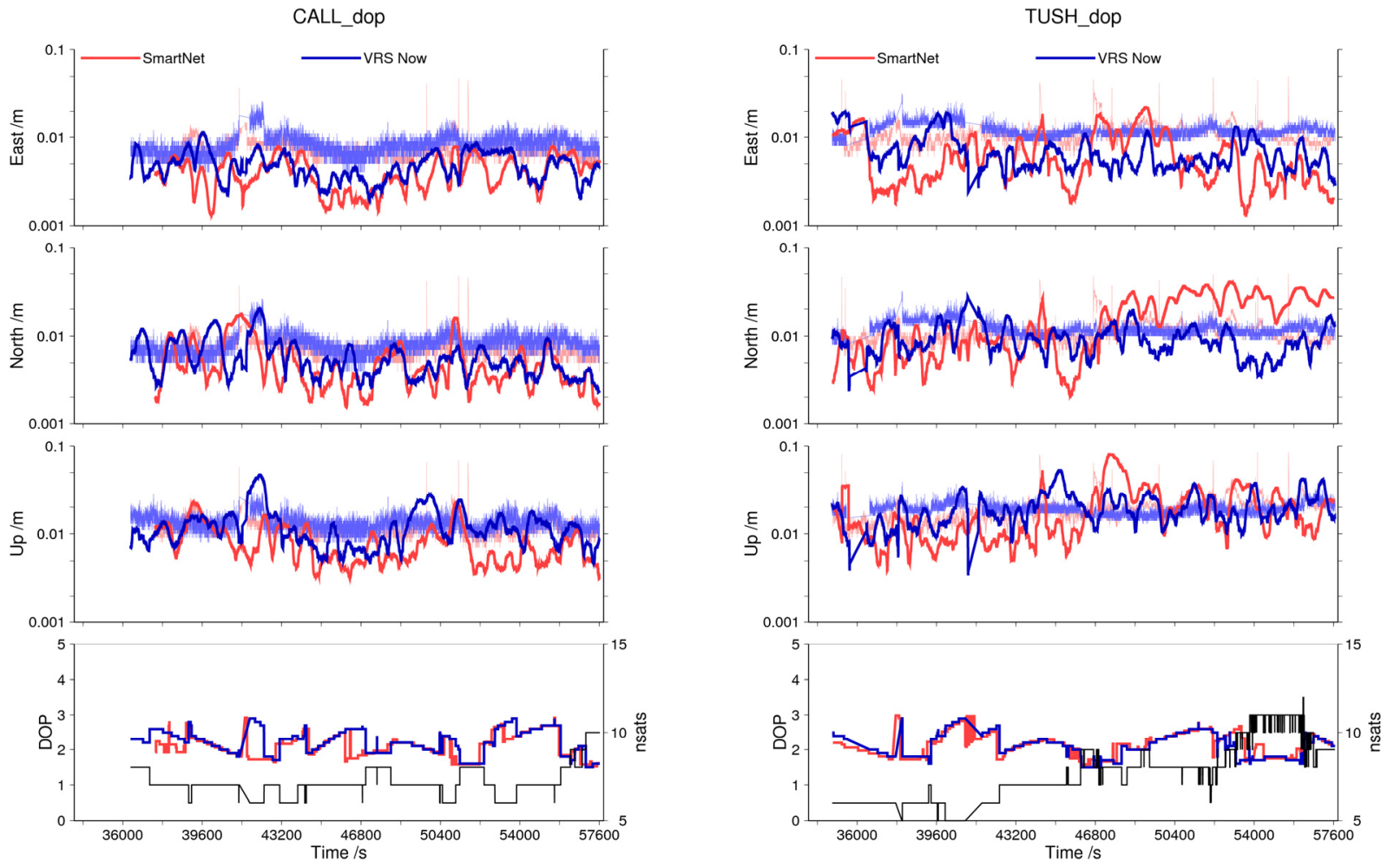

Fig 5. Manufacturer-derived CQ values (thin lines) and RMS position errors (thick lines, computed every second using a 5 minute moving window) for CALL and TUSH.

170308 CALL_dop CQ ratio

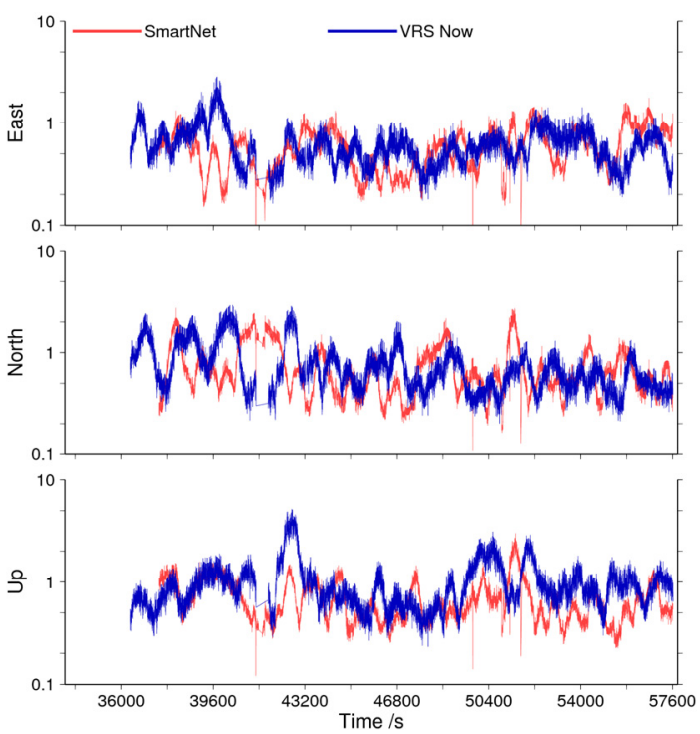

170408 TUSH_dop CQ ratio

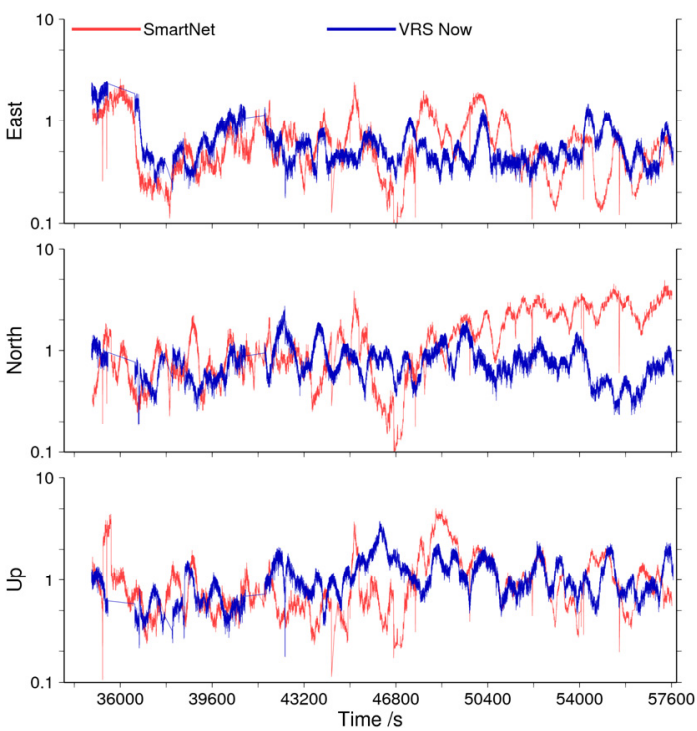

Fig 6. Ratios of moving-window RMS position error to manufacturer-derived CQ values for CALL and TUSH. 
Table 2. Position errors and CQ values for all test sites (after application of $C Q$ and DOP filters), and total percentage of observations removed by the filters.

\begin{tabular}{|c|c|c|c|c|c|c|c|c|}
\hline Site & Network & $\begin{array}{l}E \\
N \\
U\end{array}$ & $\begin{array}{c}\text { Min. } \\
(\mathrm{mm})\end{array}$ & $\begin{array}{l}\text { Max. } \\
(\mathrm{mm})\end{array}$ & $\begin{array}{c}\text { Mean } \\
(\mathrm{mm})\end{array}$ & $\begin{array}{l}R M S \\
(\mathrm{~mm})\end{array}$ & $\begin{array}{c}R M S / C Q \\
\text { mean } \\
\text { ratio }\end{array}$ & $\begin{array}{r}\% \\
D O P \\
+C Q \\
\end{array}$ \\
\hline \multirow[t]{6}{*}{ CALL } & SmartNet & E & -26 & 14 & 2 & 5 & 0.596 & 0.9 \\
\hline & & $\mathrm{N}$ & -15 & 67 & 0 & 6 & 0.727 & \\
\hline & & $\mathrm{U}$ & -38 & 45 & -4 & 9 & 0.695 & \\
\hline & VRS Now & $\mathrm{E}$ & -8 & 20 & 4 & 5 & 0.622 & 2.2 \\
\hline & & $\mathrm{N}$ & -34 & 17 & -3 & 7 & 0.764 & \\
\hline & & $\mathrm{U}$ & -69 & 52 & -9 & 14 & 0.977 & \\
\hline \multirow[t]{6}{*}{ STMG } & SmartNet & E & -33 & 65 & 8 & 32 & 2.847 & 3.4 \\
\hline & & $\mathrm{N}$ & -44 & 16 & -10 & 15 & 1.268 & \\
\hline & & $\mathrm{U}$ & -18 & 68 & 24 & 30 & 1.634 & \\
\hline & VRS Now & $\mathrm{E}$ & -55 & 56 & 8 & 28 & 2.302 & 0.9 \\
\hline & & $\mathrm{N}$ & -23 & 44 & 7 & 11 & 0.952 & \\
\hline & & $\mathrm{U}$ & -62 & 68 & 6 & 19 & 1.003 & \\
\hline \multirow[t]{6}{*}{ TRET } & SmartNet & $\mathrm{E}$ & -38 & 28 & -1 & 7 & 0.585 & 0.1 \\
\hline & & $\mathrm{N}$ & -27 & 48 & 6 & 10 & 0.880 & \\
\hline & & $\mathrm{U}$ & -64 & 42 & -7 & 19 & 0.963 & \\
\hline & VRS Now & $\mathrm{E}$ & -31 & 23 & 1 & 7 & 0.577 & 1.6 \\
\hline & & $\mathrm{N}$ & -28 & 34 & 11 & 13 & 1.133 & \\
\hline & & $\mathrm{U}$ & -70 & 67 & -9 & 18 & 0.904 & \\
\hline \multirow[t]{6}{*}{ STRE } & SmartNet & E & -21 & 39 & 7 & 9 & 0.840 & 0.1 \\
\hline & & $\mathrm{N}$ & -11 & 85 & 13 & 20 & 1.308 & \\
\hline & & $\mathrm{U}$ & -142 & 43 & 0 & 24 & 1.024 & \\
\hline & VRS Now & $\mathrm{E}$ & -14 & 30 & 6 & 9 & 0.759 & 2.1 \\
\hline & & $\mathrm{N}$ & -21 & 32 & 9 & 11 & 0.980 & \\
\hline & & $\mathrm{U}$ & -64 & 83 & -1 & 14 & 0.816 & \\
\hline \multirow[t]{6}{*}{ TUSH } & SmartNet & $\mathrm{E}$ & -61 & 25 & -4 & 8 & 0.655 & 3.3 \\
\hline & & $\mathrm{N}$ & -127 & 62 & 13 & 19 & 1.424 & \\
\hline & & U & -110 & 566 & -14 & 24 & 1.049 & \\
\hline & VRS Now & $\mathrm{E}$ & -42 & 33 & -1 & 8 & 0.600 & 4.9 \\
\hline & & $\mathrm{N}$ & -33 & 37 & 5 & 10 & 0.773 & \\
\hline & & $\mathrm{U}$ & -81 & 89 & -11 & 22 & 1.060 & \\
\hline \multirow[t]{6}{*}{ GWYN } & SmartNet & $\mathrm{E}$ & -56 & 35 & 3 & 9 & 0.761 & 8.1 \\
\hline & & $\mathrm{N}$ & -48 & 52 & 2 & 10 & 0.842 & \\
\hline & & U & -107 & 106 & 21 & 30 & 1.526 & \\
\hline & VRS Now & $\mathrm{E}$ & -73 & 51 & 1 & 14 & 0.823 & 6.3 \\
\hline & & $\mathrm{N}$ & -128 & 54 & 5 & 18 & 0.975 & \\
\hline & & $\mathrm{U}$ & -167 & 82 & -13 & 29 & 1.199 & \\
\hline
\end{tabular}




\section{NETWORK EXTREMITIES AND OCEAN TIDE LOADING EFFECTS}

Having determined that both SmartNet and VRS Now provide height accuracies and precisions of better than $30 \mathrm{~mm}$ in height and $20 \mathrm{~mm}$ in plan, the factors contributing to degradation in performance compared with the ideal test site CALL were considered. Firstly, the effect of extrapolating coordinate corrections due to the test site being located on the edge of the network rather than being surrounded by reference stations was considered. The two test sites STMG and TRET were used for this, since they were both on the edges of the network and not surrounded by reference stations. It can be seen from Table 2 that for STMG the RMS errors are 15, 32 and $30 \mathrm{~mm}$ in North, East, and Up respectively for SmartNet and similarly 11, 28 and $19 \mathrm{~mm}$ for VRS Now. Comparable figures for TRET are 10, 7 and $19 \mathrm{~mm}$ for SmartNet and 13, 7 and $18 \mathrm{~mm}$ for VRS Now. These RMS errors are worse than those at the CALL control test site $(6,5,9 \mathrm{~mm}$ for SmartNet and 7, 5, $14 \mathrm{~mm}$ for VRS Now) and hence suggest that positional quality is indeed degraded at the network extents due to the need to extrapolate rather than interpolate corrections. In addition to these statistics derived from 6 hours of continuous data, it should be noted that there were instances when epoch-to-epoch excursions of up to $30 \mathrm{~mm}$ for TRET and significantly larger for STMG arose; no such excursions occurred at CALL. The large STMG East/West RMS errors for both SmartNet and VRS Now arise from almost decimetre level errors that persist throughout the observation period, and are likely caused by interference. In caution, it should be noted that during the truth coordinate determination this was also the only site for which ambiguity resolution success rates were less than $90 \%$, being only $60-70 \%$.

TRET was also chosen for this study since it is subject to relatively large OTL effects (absolute vertical displacement of about $3 \mathrm{~cm}$ due to the largest ocean tidal constituent, M2, with a period of $12 \mathrm{~h} 25 \mathrm{~m}$ ) and therefore offered a potential opportunity to assess the sensitivity of Network RTK to OTL effects, which were not modelled in the solutions. However, for relative GPS positioning as used in Network RTK, it is the difference of the OTL displacement between rover and reference stations that is important, rather than the absolute displacement at the rover. This is considered in detail by [13], who show that the maximum residual OTL errors in the vicinity of TRET could range from 3-8 mm dependent on the interpolation / extrapolation approach used by the Network RTK service providers. Correcting the 6 hours of Network RTK height estimates for TRET with residual OTL displacements computed according to the four interpolation / extrapolation methods of [13] and using the FES2004 ocean tide model [17], resulted in reductions in the absolute RMS error in every case for both SmartNet (up to 5.7\%) and VRS Now (up to 7.3\%).

\section{HEIGHT EFFECTS}

One of the challenges when using any GNSS technique is the mitigation of tropospheric effects. Traditionally, for static processing and single reference station RTK surveying up to distances of around $10 \mathrm{~km}$, this has been addressed by the use of differencing together with models of the 'dry' atmosphere, e.g. [18]. Key assumptions in the employment of such models are that the base and rover stations are at similar altitudes and that the baseline distances are relatively short. Clearly, these conditions cannot always be satisfied when using Network RTK and while tropospheric models remain useful, manufacturers must deal with residual tropospheric delays arising from different atmospheric conditions at the rover and reference station locations. To investigate whether any of the increased positional errors 
seen compared with the CALL control site could be attributed to tropospheric errors, sites TUSH and GWYN were considered since they were only $28 \mathrm{~km}$ apart, were observed on consecutive days when the weather was similar, yet as can be seen from Table 1, TUSH has a mean elevation difference of only $16 \mathrm{~m}$ from the nearest four reference stations, whereas for GWYN this value is $\sim 250 \mathrm{~m}$. The range of baseline distances from OS Net reference stations to both GWYN and TUSH is similar, with those for TUSH being slightly shorter. Table 2 shows that the RMS height errors are worse for GWYN than TUSH (30 and $30 \mathrm{~mm}$ for GWYN compared with 24 and $22 \mathrm{~mm}$ for TUSH for the two Network RTK services), suggesting that a large height separation and hence unmodelled tropospheric errors may degrade Network RTK positions, particularly heights. Furthermore, the height biases are greater for GWYN than for TUSH (21 and $-13 \mathrm{~mm}$ compared with -14 and $-11 \mathrm{~mm}$ ). However, the magnitude of these errors is still encouraging with regard to the overall system performance, i.e. no worse than $30 \mathrm{~mm}$. It is however possible that greater degradations than found for GWYN compared with TUSH could arise when larger height differences exist between the rover and nearest reference stations. Figure 1 shows the areas where height differences are greatest and hence the biggest errors may be expected, in mountainous areas such as Snowdonia, the Lake District and Scottish Highlands, and further testing is recommended in such areas. Besides being above the nearest reference stations, it should also be noted that Figure 1 illustrates how it is possible for the user to be significantly below the average height of the nearby reference stations.

\section{IMPROVING SOLUTION ROBUSTNESS: SingLE- AND DOUBLE-WINDOW AVERAGING}

To improve the positional quality attainable with SmartNet and VRS Now, it is possible to undertake some form of epoch-to-epoch solution averaging, thus reducing the effects of noise and any short period errors. This is particularly pertinent for precise survey applications such as the use of Network RTK to establish local control. Two key questions therefore present themselves. Firstly, what is the optimal reasonable averaging window period, given time constraints that exist in most survey tasks? Secondly, does taking the average of two such windows, separated by a time period to allow for constellation geometry change and possible change in atmospheric conditions, improve solutions further?

To answer these questions, statistics have been generated for 1, 5, 180 and 300 second samples using only a single moving window average and then for a double-window average using the average of two such windows separated by 20 or 45 minutes. These single-window and double-window average solution statistics are listed in Table 3 . Thus in regard to question (i) above the RMS errors based on a single 1 second window range from $6,8,9 \mathrm{~mm}$ to $19,14,31 \mathrm{~mm}$ in the North, East and height components respectively. Little improvement is seen for a window of 5 seconds duration. However, for a 3 minute window some small improvement can be seen particularly in the Up direction, although further averaging over a single window e.g. 5 minutes does not appear to offer much additional improvement on the determined coordinates. With regard to question (ii), results from the mean of two windows separated by 20 minutes show more substantial reductions in the rms values compared to a single window approach. For example, employing this approach at TUSH based on 5 second windows improves coordinate RMS values in the height component by $4 \mathrm{~mm}$ for both Network RTK solutions. The reason for the improvement delivered by this double window averaging approach is that the separation period is driving down short period system biases. However, beyond 45 minutes no significant advantage is derived from this technique. 
Table 3. Effect of single and double window averaging on RMS positional errors (after application of $C Q$ and DOP filters).

\begin{tabular}{|c|c|c|c|c|c|c|c|c|c|c|c|}
\hline \multirow[t]{2}{*}{ Site } & \multirow[t]{2}{*}{ Network } & \multirow{2}{*}{$\begin{array}{c}\text { Window } \\
\text { size } \\
(s)\end{array}$} & \multicolumn{3}{|c|}{ Single window } & \multicolumn{3}{|c|}{20 min separation } & \multicolumn{3}{|c|}{45 min separation } \\
\hline & & & $\begin{array}{c}E \\
(\mathrm{~mm})\end{array}$ & $\begin{array}{c}N \\
(\mathrm{~mm})\end{array}$ & $\begin{array}{c}U \\
(\mathrm{~mm})\end{array}$ & $\begin{array}{c}E \\
(\mathrm{~mm})\end{array}$ & $\begin{array}{c}N \\
(\mathrm{~mm})\end{array}$ & $\begin{array}{c}U \\
(\mathrm{~mm})\end{array}$ & $\begin{array}{c}E \\
(\mathrm{~mm})\end{array}$ & $\begin{array}{c}N \\
(\mathrm{~mm})\end{array}$ & $\begin{array}{c}U \\
(\mathrm{~mm})\end{array}$ \\
\hline \multirow{8}{*}{ CALL } & SmartNet & 1 & 5 & 6 & 9 & 4 & 5 & 8 & 3 & 4 & 7 \\
\hline & & 5 & 4 & 6 & 9 & 4 & 5 & 7 & 3 & 4 & 6 \\
\hline & & 180 & 4 & 6 & 8 & 3 & 4 & 7 & 3 & 3 & 6 \\
\hline & & 300 & 4 & 6 & 8 & 3 & 4 & 7 & 3 & 3 & 6 \\
\hline & VRS Now & 1 & 5 & 7 & 14 & 5 & 6 & 13 & 5 & 5 & 12 \\
\hline & & 5 & 5 & 7 & 14 & 5 & 6 & 13 & 5 & 5 & 12 \\
\hline & & 180 & 5 & 6 & 13 & 4 & 5 & 12 & 4 & 5 & 11 \\
\hline & & 300 & 5 & 6 & 13 & 4 & 5 & 12 & 4 & 5 & 11 \\
\hline \multirow[t]{8}{*}{ STMG } & SmartNet & 1 & 32 & 15 & 30 & 31 & 15 & 30 & 31 & 15 & 31 \\
\hline & & 5 & 32 & 15 & 30 & 31 & 15 & 30 & 31 & 15 & 31 \\
\hline & & 180 & 32 & 15 & 30 & 31 & 15 & 30 & 30 & 15 & 31 \\
\hline & & 300 & 32 & 15 & 30 & 31 & 15 & 30 & 30 & 15 & 31 \\
\hline & VRS Now & 1 & 28 & 11 & 19 & 27 & 10 & 16 & 25 & 10 & 15 \\
\hline & & 5 & 28 & 11 & 19 & 27 & 10 & 15 & 25 & 9 & 14 \\
\hline & & 180 & 28 & 11 & 17 & 26 & 10 & 14 & 24 & 9 & 13 \\
\hline & & 300 & 28 & 10 & 17 & 26 & 9 & 14 & 24 & 9 & 13 \\
\hline \multirow[t]{8}{*}{ TRET } & SmartNet & 1 & 7 & 10 & 19 & 5 & 9 & 15 & 5 & 9 & 16 \\
\hline & & 5 & 7 & 10 & 19 & 5 & 9 & 15 & 5 & 9 & 16 \\
\hline & & 180 & 6 & 10 & 16 & 4 & 8 & 13 & 4 & 8 & 14 \\
\hline & & 300 & 6 & 9 & 15 & 4 & 8 & 12 & 4 & 8 & 13 \\
\hline & VRS Now & 1 & 7 & 13 & 18 & 6 & 13 & 16 & 6 & 13 & 15 \\
\hline & & 5 & 7 & 13 & 17 & 6 & 12 & 15 & 5 & 12 & 14 \\
\hline & & 180 & 6 & 13 & 16 & 5 & 12 & 14 & 5 & 12 & 13 \\
\hline & & 300 & 6 & 13 & 16 & 5 & 12 & 14 & 5 & 12 & 12 \\
\hline \multirow[t]{8}{*}{ STRE } & SmartNet & 1 & 9 & 20 & 24 & 8 & 19 & 20 & 8 & 18 & 18 \\
\hline & & 5 & 8 & 20 & 23 & 8 & 19 & 20 & 8 & 18 & 18 \\
\hline & & 180 & 8 & 20 & 22 & 8 & 19 & 19 & 8 & 17 & 17 \\
\hline & & 300 & 8 & 20 & 22 & 8 & 19 & 19 & 8 & 17 & 16 \\
\hline & VRS Now & 1 & 8 & 11 & 14 & 8 & 11 & 11 & 8 & 11 & 11 \\
\hline & & 5 & 8 & 11 & 13 & 7 & 10 & 10 & 7 & 10 & 10 \\
\hline & & 180 & 8 & 11 & 11 & 7 & 10 & 8 & 7 & 10 & 8 \\
\hline & & 300 & 8 & 10 & 10 & 7 & 10 & 7 & 7 & 10 & 7 \\
\hline \multirow[t]{8}{*}{ TUSH } & SmartNet & 1 & 8 & 19 & 24 & 7 & 18 & 20 & 6 & 18 & 21 \\
\hline & & 5 & 8 & 19 & 24 & 7 & 18 & 20 & 6 & 18 & 21 \\
\hline & & 180 & 8 & 19 & 22 & 6 & 18 & 19 & 6 & 18 & 19 \\
\hline & & 300 & 7 & 19 & 21 & 6 & 18 & 19 & 6 & 18 & 19 \\
\hline & VRS Now & 1 & 8 & 10 & 22 & 7 & 9 & 18 & 6 & 8 & 18 \\
\hline & & 5 & 8 & 10 & 22 & 7 & 8 & 17 & 6 & 8 & 17 \\
\hline & & 180 & 7 & 8 & 19 & 6 & 7 & 16 & 5 & 7 & 16 \\
\hline & & 300 & 7 & 8 & 18 & 6 & 7 & 15 & 5 & 7 & 15 \\
\hline \multirow[t]{8}{*}{ GWYN } & SmartNet & 1 & 9 & 10 & 30 & 7 & 8 & 27 & 7 & 7 & 26 \\
\hline & & 5 & 9 & 10 & 30 & 7 & 7 & 27 & 7 & 7 & 26 \\
\hline & & 180 & 9 & 9 & 29 & 7 & 7 & 26 & 7 & 6 & 25 \\
\hline & & 300 & 8 & 8 & 28 & 6 & 6 & 25 & 6 & 5 & 24 \\
\hline & VRS Now & 1 & 14 & 18 & 29 & 11 & 14 & 23 & 9 & 14 & 23 \\
\hline & & 5 & 13 & 17 & 29 & 11 & 13 & 22 & 9 & 13 & 22 \\
\hline & & 180 & 12 & 16 & 26 & 10 & 12 & 20 & 8 & 12 & 20 \\
\hline & & 300 & 12 & 15 & 25 & 10 & 11 & 19 & 7 & 12 & 19 \\
\hline
\end{tabular}


Clearly the use of single and double window averaging is useful in reducing the effects of noise, random errors and solution degradations due to poor satellite geometry. However, they cannot be used to reduce ocean tide loading errors, since these are systematic errors with roughly 12 and 24 hour periods, and repeat observations over a longer time span will be required. A method is provided, [13], to firstly assess the effect of ocean tide loading on a Network RTK solution by taking three sets of measurements each separated by 3 hours, and it is demonstrated that it can be largely eliminated by taking two sets of measurements roughly 6 hours apart.

\section{CONCLUSIONS}

This study has provided an assessment of the performance of the two Network RTK services available in Great Britain as of March 2009, namely SmartNet and VRS Now, both of which make use of the Ordnance Survey's national CORS geodetic infrastructure, i.e. OS Net. With caution, we suggest that our results may be broadly applicable to other networks in regions which have similar CORS spacing. By simultaneously collecting 6 hours of data from each system at six test sites across England and Wales, each subject to differing distances from the nearest reference stations both horizontally and in height, and both within the heart and on the extremities of the network, we have confirmed that the positional precision (one-sigma) attainable with both systems is $10-20 \mathrm{~mm}$ in horizontal and $15-30 \mathrm{~mm}$ in height, with small biases of a up to a few millimetres $(5-20 \mathrm{~mm}$ in height). The system performance figures quoted were obtained after applying CQ filters of $50 \mathrm{~mm}$ in horizontal and $100 \mathrm{~mm}$ in height, plus a DOP filter of 3 (rather than the commonly used 5), although such filters have minimal effect on position availability. In general, the one-sigma coordinate quality indicators provided with both the SmartNet and VRS Now solutions were found to be representative, although short deviations did arise over up to 30 min time spans.

The positional quality was found to degrade slightly $(5-15 \mathrm{~mm}$ in plan and height) when the rover was outside the bounds of the network, i.e. when error corrections are extrapolated rather than interpolated.. Position quality was also degraded for greater rover to reference station mean elevation differences due to unmodelled tropospheric delay effects, with RMS height errors increasing by $5-8 \mathrm{~mm}$ for an increase in mean elevation difference of $250 \mathrm{~m}$. OTL was also found to contribute to the error budget, with up to 7\% RMS reductions in the height RMS error found when correcting for it at TRET in South-west Wales.

If the coordinate quality attainable from single epoch Network RTK is inadequate, we found that solution quality and robustness can be improved by implementing either single- or double-window position averaging. For topographic survey applications, a 5 second singlewindow average reduces the effect of individual coordinate solution variations, but for more precise work, using two sets of averaged windows of around 3 minutes separated by around 20 minutes was found to yield $10-20 \%$ coordinate accuracy improvements compared with a single epoch solution. This could be further improved to up to $30 \%$ if the double window separation was extended to about 45 minutes, but beyond this separation no appreciable improvement was obtained. 


\section{ACKNOWLEDGEMENTS}

Newcastle University was commissioned to undertake this evaluation of Network RTK services available in Great Britain by five project stakeholders, namely TSA (represented by Richard Otto, Bernhard Becker and Rory Stanbridge); Leica Geosystems (Mark Burbidge); Trimble (Anthony Mills); Ordnance Survey (Paul Cruddace) and RICS (James Kavanagh), whose funding and project input are gratefully acknowledged. The project led to the development and release of a set of Best Practice Guidance Notes for Network RTK Surveying in Great Britain, available from www.tsa.org.uk. Martin Robertson (Newcastle University) is thanked for project fieldwork and data collection support. Figures were produced using the public-domain Generic Mapping Tools software [19].

\section{References}

1. Euler, H.-J., Zebhauser, B.E., Townsend, B. and Wübbena, G., 2002. Comparison of Different Proposals for Reference Station Network Information Distribution Formats, ION GPS 2002, 24-27 September 2002, Portland, OR, USA.

2. Vollath, U., Buecherl, A., Landau, H., Pagels, C. and Wagner, B., 2000a. Multi-Base RTK Positioning Using Virtual Reference Stations, ION GPS 2000, 19-22 September, Salt Lake City, UT, USA.

3. Vollath, U., Buecherl, A., Landau, H., Pagels, C. and Wagner, B., 2000b. LongRange RTK Positioning Using Virtual Reference Stations, ION GPS 2000, 19-22 September, Salt Lake City, UT, USA.

4. Hu, G., Khoo, H.S., Goh, P.C. and Law, C.L. 2003. Development and Assessment of GPS Virtual Reference Stations for RTK Positioning, Journal of Geodesy, 77(5-6): 292-302.

5. Ong Kim Sun, G., and Gibbings, P., 2005. How well does the Virtual Reference Station (VRS) System of GPS Base Stations Perform in Comparison to Conventional RTK?, Journal of Spatial Science, 50(1): 59-73.

6. Leica Geosystems, 2009, Leica SmartNet, Frequently Asked Questions, http://smartnet.leica-

geosystems.co.uk/SpiderWeb/SmartNet/2eFAQ.html\#whatissmartnet. Last accessed 9 April 2009.

7. Trimble, 2005. The Impact of Modernized GPS and Galileo on Network RTK, Technology and More (Trimble Newsletter for Surveying and Mapping), 2: 4-5.

8. Eren, K., Uzel, T., Gulal, E., Yildirim, O. and Cingoz, A., 2009. Results from a Comprehensive Global Navigation Satellite System Test in the CORS-TR Network: Case Study, Journal of Surveying Engineering, 135(1): 10-18.

9. Takac, F. and Lienhart, W, 2008. SmartRTK: A Novel Method of Processing Standardised RTCM Network RTK Information for High Precision Positioning, Proceedings of ENC GNSS 2008, 22-25 April 2008, Toulouse, France. 
10. Wei, E., Chai, H., An, Z. and Liu, J., 2006. VRS Virtual Observations Generation Algorithm, Journal of Global Positioning Systems, 5(1-2): 76-81.

11. Aponte, J., Meng, X., Hill, C., Moore, T., Burbidge, M. and Dodson, A., 2009. Quality Assessment of a Network-based RTK GPS Service in the UK, Journal of Applied Geodesy, 3(1): 25-34.

12. Aponte, J., Meng., X., Moore, T., Hill, C. and Burbidge, M., 2009. Assessing Network RTK Wireless Delivery, GPS World, February 2009.

13. Clarke, P.J. and Penna, N.T., under review. Ocean Tide Loading and Relative GNSS in the British Isles, Survey Review, submitted April 2009.

14. Dach, R., Hugentobler, U., Fridez, P. and Meindl, M., 2007. Bernese GPS Software Version 5.0, User Manual.

15. McCarthy, D.D. and Petit, G., 2004. IERS Conventions 2003. IERS Technical Note 32.

16. Lyard, F., Lefévre, F., Letellier, T. and Francis, O., 2006. Modelling the Global Ocean Tides: Modern Insights from FES2004, Ocean Dynamics, 56(5-6): 394-415.

17. Niell, A., 1996. Global Mapping Functions for the Atmospheric Delay at Radio Wavelengths, Journal of Geophysical Research, 101: 3227-3246.

18. Saastamoinen, J., 1973. Contributions to the Theory of Atmospheric Refraction, Bulletin Geodesique (in three parts), 105: 279-298, 106: 383-397, 107: 13-34.

19. Wessel, P. and Smith, W. H. F., 1991. Free software helps map and display data, EOS Trans. $A G U, 72: 441$. 